\title{
Sexual Harassment of Students: What I Learned in the Library
}

\author{
Kay Lehman Schlozman, Boston College
}

In comparing notes with my women friends about our experiences in graduate school two decades ago, I have become aware that we once considered the predatory behaviors of some professors as being something like crime on campus-another hazard, to be avoided if possible, that came with the territory. We tolerated unwanted attentions from faculty, not because they had no negative consequences for our emotional well-being or academic progress, but because we believed that nothing could be done about them. Since then, however, such behavior has gained a name, "sexual harassment," and has been declared illegal.

When it became obvious last spring that the university where I teach was not exempt from the problem, I behaved like a typical academic: I went to the library. What I read in the substantial scholarly literature about sexual harassment on campuses made clear that many faculty misperceive the nature and the extent of the problem-because our information comes from a few newsworthy but atypical cases and because, if we talk about such matters at all, we are more likely to talk with other faculty than with victims.

Sexual harassment refers to unwanted sexual attention. It can involve people in different kinds of relationships on a college campusfellow students, colleagues on the faculty, supervisors and employeesas well as students and faculty. When a faculty member harasses a student, however, the abuse is especially severe, for what is violated is not only a relationship of authority but also, appropriately, one of trust.

There is some difference of opinion on campuses as to what constitutes sexual harassment by faculty. One study conducted at a large private research university (Verba et al. 1983: 8-12) showed near unanimity in considering unwanted touching, or pressure for dates, or sexual activity by faculty to be sexual harassment; somewhat lower proportionsthough still solid majorities-deemed unwanted teasing, jokes, or remarks of a sexual nature or sexually suggestive looks or gestures to be sexual harassment; still lower proportions considered sex-stereotyped jokes or references to be sexual harassmentwith males and senior faculty less likely to express concern than females, junior faculty, and students.

When a faculty member
harrasses a student,
however, the abuse is
especially severe, for what
is violated is not only a
relationship of authority
but also, appropriately,
one of trust.

In developing policy on sexual harassment, many universities, as well as the APSA, have adapted the Equal Opportunity Employment Commission's guidelines to an academic setting. These guidelines specify an inclusive definition of sexual harassment encompassing verbal as well as physical advances and the creation of a hostile environment as well as threats of retaliation. According to the APSA's definition (“APSA Policy Statement"), sexual harassment includes:

Unwelcome sexual advances, requests for sexual favors, and other verbal or physical conduct of a sexual nature when:

1. submission to such conduct is made either explicitly or implicitly a term or condition of an individual's employment or academic achievement, or

2. submission to or rejection of such conduct by an individual is used as the basis for employment decisions or academic decisions affecting such individuals, or

3. such conduct has the purposes or effect of unreasonably interfering with an individual's work or academic performance or creating an intimidating, hostile, or offensive working or academic environment.

Sexual harassment that involves coercive sexual conduct, including suggestions that academic or employment reprisals or rewards will follow the refusal or granting of sexual favors, constitutes moral turpitude or gross misconduct in the sense that these terms are used in university tenure regulations, and therefore constitutes grounds for dismissal.

Academic literature refutes two contentions often made about sexual harassment. The first is that sexual harassment is not widespread but only seems to be as the result of publicity generated by a few notorious cases. Unfortunately, however, study after study demonstrates this to be false. There is remarkable consistency among surveys conducted on campuses in showing that sexual harassment of students is relatively common. All of them find that between $20-30 \%$ of female students have been victims of sexual harassment. ${ }^{1}$ It is important to note that these figures incorporate all manifestations of sexual harassment including the milder verbal forms. Lower proportions-under $10 \%$ - have been subjected to the more severe variants such as unwelcome touching, or pressure for dates, or sexual favors. Even if only $2 \%$ of women students had had such experiences, however, this would mean well over 100,000 people. Furthermore, these data conflate newly arrived freshmen, who are relatively unlikely to report having been victims of sexual harassment, with students who have been on campus for longer periods of time. One study (Verba et al.: 42-44) stratified the respondents by year in college and found that $48 \%$ of the senior women had experienced 
some sexual harassment, $20 \%$ reporting a serious or very serious incident. $^{2}$

...48\% of the senior women had experienced some sexual harassment, $20 \%$ reporting a serious or very serious incident.

The results of studies based on self-reporting of the victims are confirmed by other sources. Such academic administrators as student affairs staff and ombudsmen affirm that the figures that emerge from the surveys are not out of line (Dziech and Weiner 1982: 15). Moreover, in one survey (Fitzgerald et al. 1988) of 235 male faculty at a large research university which inquired about various kinds of interactions with students including lending books, acting as a mentor, encouraging talented students to apply to graduate school, and the like, $26 \%$ of the respondents indicated that they had had a sexual encounter with a student at some point. While this figure encompasses an unknown number of relationships (including some that led to marriage) that would not be considered as sexual harassment, the figure is probably too low, with respondents more likely to fail to report such incidents on a survey than to exaggerate them.

The studies are unanimous that the student victims of harassment are overwhelmingly, though not exclusively, female. Furthermore, the harassers are even more overwhelmingly male. Interestingly, it seems that male students who report having been harassed are more likely to have been harassed by a male than by a female (Verba et al. 1983: 42). Moreover, although none of the studies contains systematic data to confirm the impression, they suggest that sexual harassment often involves multiple infractions (Dziech and Weiner 1984: 36); that is, that a single reported incident of sexual harassment may be part of a pattern of behavior by the faculty member involved. ${ }^{3}$ Finally, anecdotal evidence to the contrary, sexual harassment does not respect disciplinary boundaries. While those in certain fieldsfor example, psychology-are sometimes cited as frequent offenders, and while certain settings such as science labs are often mentioned as conducive to sexual harassment, systematic data show that no field, including political science, has been spared involvement.

. . . the student victims

\section{of harassment are over- whelmingly, though not exclusively, female.}

These studies discredit a second assertion that is frequently made about sexual harassment-namely, that, while regrettable, it does not really matter very much. All the studies argue strongly to the contrary -that sexual harassment has consequences, sometimes severe ones, for victims. Most often, the experience is psychologically upsetting; somewhat less often, it is damaging to academic performance. One study (Verba et al. 1983: 31-39) showed that about half of those indicating an incident of sexual harassment said that it affected their academic performance -for example, they had difficulty studying, skipped class in order to avoid the offender, or changed thesis advisers. In some cases victims have changed fields or dropped out of school. The actual cases described in these studies make for moving reading; they are reminders that beneath the statistics are real students whose lives have been disrupted.

Students who are victimized by sexual harassment use many different strategies to cope: most ignore it, saying nothing or, perhaps, talking to a friend; a large number attempt to avoid the harasser by skipping - class or dropping the course; a minority confront the harasser-a strategy with uncertain consequences. All the studies are in agreement, however, that almost nobody brings the matter to the attention of those empowered to do something about the situation. Informal complaints to the administration are very rare: less than $5 \%$ of victims discuss the matter with an administrator. Formal proceedings are truly exceptional, being invoked by less than $1 \%$ of sexual harassment victims.

. . . almost nobody brings

the matter to the attention of those empowered to do something about the situation.

Why do so few victims report incidents of sexual harassment? All of the studies mention the same inhibiting factors: embarrassment and shame; uncertainty as to whether the incident constituted harassment; lack of knowledge as to where to go; desire not to get the harasser into trouble; belief that the university would be unresponsive or that nothing would be done; and fear of reprisals. The one study (Verba et al. 1983: 50-52) that quantified the reasons for failure to report an incident found that just over half of the victims indicated that fear of retaliation was a reason for not reporting an incident.

Empirical studies of sexual harassment also shed light on the fears most often expressed by facultyincluding the majority who are innocent of wrongdoing. One concern, presumably growing out of the publicity given to a few cases by the media, is that a witch-hunt mentality will result in punishments out of proportion to the offense.

However, one result of the dearth of formal complaints is that sanctions for sexual harassment are exceedingly rare. Even the most frequent punishment, a verbal warning to the offender, is seldom invoked. More severe forms of discipline-a letter in the harasser's permanent file, forced leave, or dismissal-are used even less often. A study (Robertson et al. 1988: 799) based on a national survey of administrators at 311 colleges and universities (which enroll $22 \%$ of all higher education students) concluded, in short, that "It seems that, faculty fears to the contrary, institutions seldom have 
levied career-damaging sanctions for sexual harassment."

... faculty fears to the contrary, institutions seldom have levied careerdamaging sanctions for sexual harassment.

Perhaps even more pervasive than concern about unduly harsh punishments is the fear of false accusations. Our system of justice is predicated upon a concern for the rights of the accused including, quite fundamentally, the presumption of innocence until proven guilty. Faculty are legitimately anxious that these principles should apply within the academy as well. While the studies of sexual harassment will not fully allay faculty concerns, they do provide some relevant data. The survey of college administrators (Robertson et al. 1988: 800) concludes that less than $1 \%$ of all complaints are false. ${ }^{5}$ Taken with the evidence about the infrequency of sanctions these data suggest that faculty fears about careers ruined by fraudulent accusations are, if not groundless, certainly magnified. Still, in light of the potential for abuse, it seems appropriate that many universities have included in their policies for handling sexual harassment cases a statement indicating that accusations that are knowingly false will themselves be considered to be violations of the policy.

That fabricated complaints are infrequent does not imply, however, that all faculty accused of harassment will concur that the accusation is fair. The anecdotal evidence makes clear that this is an area fraught with misunderstanding: what is viewed by the faculty member as humor, friendly concern, or the appropriate response to mutual sexual attraction may be interpreted by a student as prejudice or unwanted attention founded upon coercion. A corollary to this theme is frequently expressed by both male and female faculty who are sensitive to the possibilities for misunderstanding: that concern and interest that should be legitimate within an academic context will be misinterpreted as sexual interest and, thus, that concern for sexual harassment will have a chilling effect on faculty-student relations (Verba et al. 1983: 61-64). ${ }^{6}$

A related faculty concern is how to deal with flirtatious or seductive behavior by students - sometimes called "hassling"- which may be a calculated effort to seek academic preferment. (On hassling, see Dziech and Wiener 1984: $24 \mathrm{ff}$.) Although none of the studies presents systematic evidence, such behavior on the part of students is hardly unknown. Furthermore, it can be annoying and disruptive to a faculty member's life. From the perspective of university policy, however, it is not simply another form of sexual harassment because the authority relations are reversed. Professors who are hassled do not need to share the fears of students who are harassed: that they will suffer retaliation if they rebuff the overture or confront the hassler; or that they will not be believed if they blow the whistle.

Still another concern frequently expressed by faculty is how to deal with genuine romance. Although there are differences of opinion as to just how inevitable they are, it would be foolish to deny that sexual attractions can result when men and women work together closely. Besides, we all know of long and happy marriages between professors and their former students. When romantic alliances between teacher and student enter the classroom, however, the prospects for the kind of misunderstanding mentioned before-in which what seems consensual to a faculty member is construed as coercive by a student-are enhanced. Furthermore, such relationships carry the possibility of unfairness to other students in competition for academic rewards because the student involved with the professor may benefit from favoritism. In light of these competing concerns, it has been suggested (Keller 1990) that universities take a middle ground in designing policy. Rather than having no policy whatsoever or banning romantic involvements between faculty and students altogether, universities can, for example, proscribe such relationships in any context in which a faculty member supervises the student's academic work and require faculty to avoid any supervisory or evaluative role with students with whom they have been romantically involved in the past.

A final theme articulated by faculty is one that partakes of a larger campus controversy: how to reconcile norms of academic freedom with attempts to restrict verbal harassment. As political scientists we are aware of how often concern about freedom of speech comes into direct conflict with another cherished value. Not surprisingly, the literature that I read provides no assistance in resolving this dilemma. However, it does make clear that education may be just as effective as censorship for what is perceived as verbal harassment may, in fact, reflect misunderstanding and miscommunication. Comments that are intended as complimentary or humorous by a benign, but insensitive, professor may be interpreted as gratuitous sexism by a student. A commitment to freedom of expression implies the need to protect the right to speak offensively; however, nothing compels people of good will to exercise that right. While it would violate norms of academic freedom to place a gag rule on sexist statements, remarks about women's appearance, or potentially offensive jokes, it does not jeopardize academic freedom to suggest the exercise of greater sensitivity and an awareness that what is said may not be heard as it was intended.

A commitment to freedom of expression implies the need to protect the right to speak offensively; however, nothing compels people of good will to exercise that right.

Ironically, sexual harassment by faculty is, in many ways, related to that which is best about academic 
life. It is appropriate that faculty should be concerned about students and available to give advice about their academic fortunes, personal lives, and future prospects. Yet such concern can be used as a smoke screen to justify harassment. Furthermore, the norms of academic freedom, faculty autonomy, and collegiality that make the professorial life an enviable one-along with the fact that campuses tend to be relatively tolerant of eccentricity-imply both that sexual harassment is difficult to apprehend and that colleagues are unlikely to want to get involved when an incident comes to light. Yet, the data about the extent of sexual harassment would suggest that, if we do not make an attempt to police ourselves, we may find ourselves policed by others less respectful of the norms that govern academic life. In short, I am concerned about sexual harassment not only because I wish to protect the student victims, but also because I wish to safeguard the norms of academic freedom, faculty autonomy, and collegiality for myself.

\section{Notes}

1. Dziech and Weiner (1984: 13-15) and Paludi (1990: 271-72) give extensive references to studies of the incidence of sexual harassment. Among other relevant studies are Verba et al. (1983), Benson and Thomson (1982); Lott et al. (1982); and Roscoe et al. (1987).

In all these studies, the strategy of inquiry is to ask about experience with particular behaviors-such as being subjected to unwanted touching or requests for datesrather than to ask a general question about having "been a victim of sexual harassment." Many students who have had experiences that would be defined as sexual harassment under the law do not know it and, therefore, give false negative answers to such a general question.

2. It is useful to understand how these incidents were categorized. Respondents who reported harassment incidents were asked to describe what happened. On the basis of several criteria-including the type of act, the number of times it was repeated, the threat of reprisal, the extent of the authority of the harasser over the victim, and the nature of the impact on the victim's emotional wellbeing or academic performance-the incidents were placed in five categories ranging from the least to the most serious. An incident categorized as "serious" (4) had to involve the "Repeated remarks and looks or gestures, and/or pressure for dates or touching and other physical contact. Subject worries about reprisals, avoids individual at some cost, such as missing class or forgoing needed help or advice. Incident(s) more traumatic because subject cannot avoid harasser (esp. resident tutor, proctor). Behavior repeated; does not stop at request. Behavior disturbing." In order to be categorized as "very serious" (5), an incident had to involve "In addition to the characteristics of category 4 , reprisals threatened or used. High level of personal or academic upset" (40-41). The Verba report contains many examples of these verbatim descriptions along with the coder's categorizations so that the reader can determine whether the categorizations are appropriate.

3. A 1981 study of federal government employees (cited in Fitzgerald and Weitzman 1990: 131) found that $43 \%$ of all victims of harassment (or $93 \%$ of all who knew whether the harasser had bothered others) indicated that the person who had harassed them had behaved similarly towards others. Only $3 \%$ of victims (or $7 \%$ of those who knew) reported being sure that no one else had been bothered.

That sexual harassment often involves patterns of behavior on the part of harassers poses puzzling dilemmas for university policy. On one hand, experience shows that informal procedures work best for handling sexual harassment cases. If procedures are unduly rigid or if they require the immediate filing of written complaints, students will be even more reluctant to report incidents and even more concerned about the possibility of retaliation. On the other hand, sole reliance on informal procedures inhibits the development of the kind of institutional memory that would permit the discernment of single from multiple offenders.

4. It is useful to note that substantially higher proportions of the victims of "serious" or "very serious" incidents indicated that fear of reprisal inhibited them from reporting an incident. Presumably, victims of less serious incidents were more likely to be among those citing uncertainty as to whether the incident constituted harassment or unwillingness to make the effort as reasons for failure to report an incident.

5. Not only are false complaints very rare, faculty are not without resources for dealing with them when they occur. Since there are rarely witnesses to acts of sexual harassment, it is usually a matter of one person's word against another's. Faculty are considerably more likely than students to possess the maturity, verbal skills, and administrative savvy to make a persuasive case when wronged.

6. The authors point out an irony here. Women students are, by and large, the victims of sexual harassment. If male faculty respond to the fear of being accused of sexual harassment by becoming distant and withdrawing attention from them, women students end up being disadvantaged in a second way as well.

\section{References}

"APSA Policy Statement on Sexual Harassment."

Benson, Donna J. and Gregg E. Thomson. 1982. "Sexual Harassment on a University Campus: The Confluence of Authority Relations, Sexual Interest, and Gender Stratification." Social Problems 29: 236-51.

Dziech, Billie Wright and Linda Weiner. 1984. The Lecherous Professor. Boston: Beacon Press.

Fitzgerald, Louise F., Lauren M. Weitzman, Yael Gold, and Mimi Ormerod. 1988. "Academic Harassment: Sex and Denial in Scholarly Garb." Psychology of Women Quarterly 12: 329-40.

Fitzgerald, Louise F. and Lauren M. Weitzman. 1990. "Men Who Harass: Speculation and Data." In Ivory Power, ed. Michele A. Paludi. Albany: State University of New York Press.

Keller, Elisabeth A. 1990. "Consensual Relationships and Institutional Policy." $\mathrm{ACa}$ deme 76 (January-February): 29-32.

Lott, Bernice, Mary Ellen Reilly, and Dale R. Howard. 1982. "Sexual Assault and Harassment: A Campus Case Study." Signs 8: 296-319.

Paludi, Michele A., ed. 1990. Ivory Power. Albany: State University of New York Press.

Robertson, Claire, Constance E. Dyer, and D'Ann Campbell. 1988. "Campus Harassment: Sexual Harassment Policies and Procedures at Institutions of Higher Learning." Signs 13: 792-812.

Roscoe, Bruce, Megan P. Goodwin, Susan E. Repp, and Marshall Rose. 1987. "Sexual Harassment of University Students and Student Employees: Findings and Implications." College Student Journal 21: 254-73.

Verba, Sidney, with Joseph DiNunzio and Christina Spaulding. 1983. "Unwanted Attention: Report on a Sexual Harassment Survey." Report to the Faculty Council of the Faculty of Arts and Sciences, Harvard University.

\section{About the Author}

Kay Lehman Schlozman is professor of political science at Boston College. Among her writings on American politics are Injury to Insult: Unemployment, Class, and Political Response, with Sidney Verba, and Organized Interests and American Democracy, with John T. Tierney. 